\title{
NEUROTROPHIC ABNORMALITIES AND DEVELOPMENT OF HIGH BLOOD PRESSURE IN GENETICALLY HYPERTENSIVE RATS
}

\author{
Christopher Bell \\ Department of Physiology, Trinity College, University of Dublin, Dublin, Ireland
}

\section{SUMMARY}

- Inbred strains ofWistar rats that spontaneously develop high blood pressure are used commonly as models of essential hypertension. In two of these strains, the spontaneously hypertensive rat and the genetically hypertensive rat, there is evidence for peripheral neurotrophic abnormalities. In the spontaneously hypertensive rat, there is elevated production of nerve growth factor, but the numbers of sympathetic and sensory neurons suggest that there may also be abnormal availability of some other neurotrophins early in development. In the genetically hypertensive rats, there is apparent decreased sympathetic access to and increased sensory access to nerve growth factor. In neither case is it clear whether or not there is any causal relationship between the neurotrophic abnormality and genesis of elevated blood pressure. The mechanistic relevance of the spontaneously hypertensive rats or the genetically hypertensive rats to the clinical syndrome of essential hypertension is similarly uncertain. However, both of these strains constitute interesting and potentially valuable systems for studying the neurotrophic regulation of normal development.

\section{INTRODUCTION}

The great majority of preclinical studies of arterial hypertension use one or another of the inbred rat strains that exhibit a hereditary predisposition for elevated blood pressure (1). Of these genetically hypertensive strains, two have been most widely characterized and both of these have been demonstrated to possess properties that are of interest to developmental neurobiologists as well as to hypertensiologists.
The two strains were both developed at nearly the same time. In 1958, Smirk and colleagues (2) in New Zealand reported the existence of the genetically hypertensive $(\mathrm{GH})$ rat strain, which had been produced by repetitive inbreeding from the descendants of a single pair of Wistar rats selected for aboveaverage blood pressures. The absolute arterial pressure levels obtained by this process rose by only a few $\mathrm{mm} \mathrm{Hg}$ with each generation, suggesting that numerous polygenes were involved, each with only a small effect. This was supported further by backcross experiments which indicated the participation of a relatively large number of genetic factors $(3,4)$. In 1962, Okamoto and Aoki (5) in Japan described the spontaneously hypertensive rats (SHR). This was also derived by inbreeding from Wistar stock, but differed from the $\mathrm{GH}$ in having developed a much more substantial degree of hypertension within the first few generations and by the fact that backcross experiments indicated the involvement of only a small number of genes in generating the hypertension $(6,7)$.

\section{See Editorial on page 5}

As human essential hypertension appears to be extremely polygenie, the GH seems likely to bear a closer resemblance to the clinical situation than does the SHR. Despite this, however, the $\mathrm{GH}$ rat has been studied relatively little. There are two main reasons for this. Because the degree of hypertension exhibited was more dramatic in early SHR generations than in GH ones, the SHR strain appeared a more attractive proposition for obtaining clear separation of data between hypertensive and control animals. Besides, the effective way in which SHR stocks were quickly made available for breeding subcolonies, rapidly 
provided a considerable body of background reference data for this strain among the international hypertensiology community.

Strikingly, the available data indicate that both SHR and GH strains are characterized not only by elevated blood pressure, which is present at the latest within a few days of birth and rises to a plateau over the first 10-12 weeks of postnatal life, but also by striking abnormalities in development of some neural crestderived peripheral neuron populations. The purpose of this review is to summarize current evidence relating to these neurotrophic defects and to assess whether or not they appear likely to be causally linked to the development of hypertension.

\section{PROPERTIES OF THE SPONTANEOUSLY HYPERTENSIVE RATS}

\section{- $\quad$ Peripheral nervous system abnormalities}

\section{- Is there sympathetic nervous system overactivity?}

The truism that sympathetic nervous system activity contributes to absolute arterial blood pressure made sympathetic overactivity an obvious candidate as a causal factor in development of hypertension in the SHR. Electrical recording from sympathetic multifibre preparations from SHR and from backcrosses with its normotensive control, the Wistar-Kyoto (WKY) strain, showed that discharge rate was increased in proportion to the degree of blood pressure elevation (8-11). Increased sympathetic drive was also suggested by observations of increased catecholamine spillover into plasma in SHR (12) and increased tissue turnover of noradrenaline (13).

On the other hand, neurochemical data on levels of neuropeptide tyrosine (NPY) in single sympathetic neurons $(14,15)$ support the presence of similar discharge rates in each strain. The absolute intracellular level of NPY has been shown to vary proportionately to neuronal activation rate (16), but similar values were found for neurons of age-matched SHR and WKY rats. In fact, there is no need to evoke increased firing frequency of individual neurons in order to explain the evidence for overall enhancement of sympathetic activity. Similar changes in the parameters measured, catecholamine spillover, and multifibre recording, would be obtained with increased activation rate of a constant axon population or with normal activation rates in a larger axon pool. Neurochemical and morphological data show that the number of sympathetic neurons is substantially increased $(25-40 \%)$ in SHR relative to WKY rats $(14,17)$ and is associated with greater density of terminal vasomotor axons $(13,15,18,19)$. Neuron numbers are elevated for both the NPY-containing phenotype, which is thought to represent cells supplying the cardiovascular system, and for the NPY-negative phenotype (15). A morphometric study has indicated that sympathetic neurons of SHR have larger dendritic fields than those of WKY rats and that this characteristics cosegregates with the elevated blood pressure (20). However, the sympathetic cell bodies themselves are not appreciably different from those of WKY rats $(15,20)$.

- Defective cell death during sympathetic nervous sys-
tem development

During normal development, 30-80\% of neurons in different parts of the nervous system are lost over the perinatal period in a process known as developmental (programmed) cell death (apoptosis) $(21,22)$. An increased population of neurons in adulthood could therefore be due either to the initial production of an increased number of neuroblasts or to reduced developmental death. In SHR pups, sympathetic cell numbers are similar to those in the WKY rat control strain at birth, when programmed sympathetic cell death has not begun (15). By contrast, two weeks later, when the period of programmed cell death is near its end, the population size is reduced by almost $50 \%$ in WKY rats but by only $22 \%$ in SHR, with similar total numbers as are seen in adulthood (15). Thus, the elevated number of sympathetic neurons in SHR cannot be ascribed to an increased number of neuroblasts but must be entirely due to reduced cell death. Developmental cell death in the nervous system is believed to result from competition within an excessively large neuron pool for limited amounts of neurotrophic factors which are produced by the target cells and gain access to the neuron via specific receptors on the axon terminals (21, 22) (Fig. la). This sequence is therefore important in providing an appropriate density of innervation to differently sized target tissues. In the case of sympathetic neurons, the neurotrophin involved is the nerve growth factor (NGF) $(23,24)$. One possible explanation for exaggerated survival of developing sympathetic neurons in the SHR would therefore be that there is enhanced availability of the antiapoptotic factor NGF (22) over the critical period of developmental cell death.

\section{- $\quad$ Increased nerve growth factor availability}

$A$ number of reports have documented increased levels of both NGF and its mRNA in sympathetic target tissues of SHR (2532). Resting NGF secretion from cultured vascular smooth muscle cells (SMC) has been found not to be elevated in SHR under normal culture conditions (33), but the ability for basal secretion from SHR cells appears to be better preserved in a serum-free medium than that of WKY rats cells (29). Turtle and colleagues have studied in detail the capacities of cultured vascular SMC to secrete NGF $(29,34)$. They have found that secretion was stimulated by stretch and by platelet-derived growth factor, and that these responses were greater in SHR than in WKY rat cells. Furthermore, SHR vascular SMC secrete NGF in response to a-adrenoceptor agonists and NPY, while WKY rat cells show little or no response to these sub- 


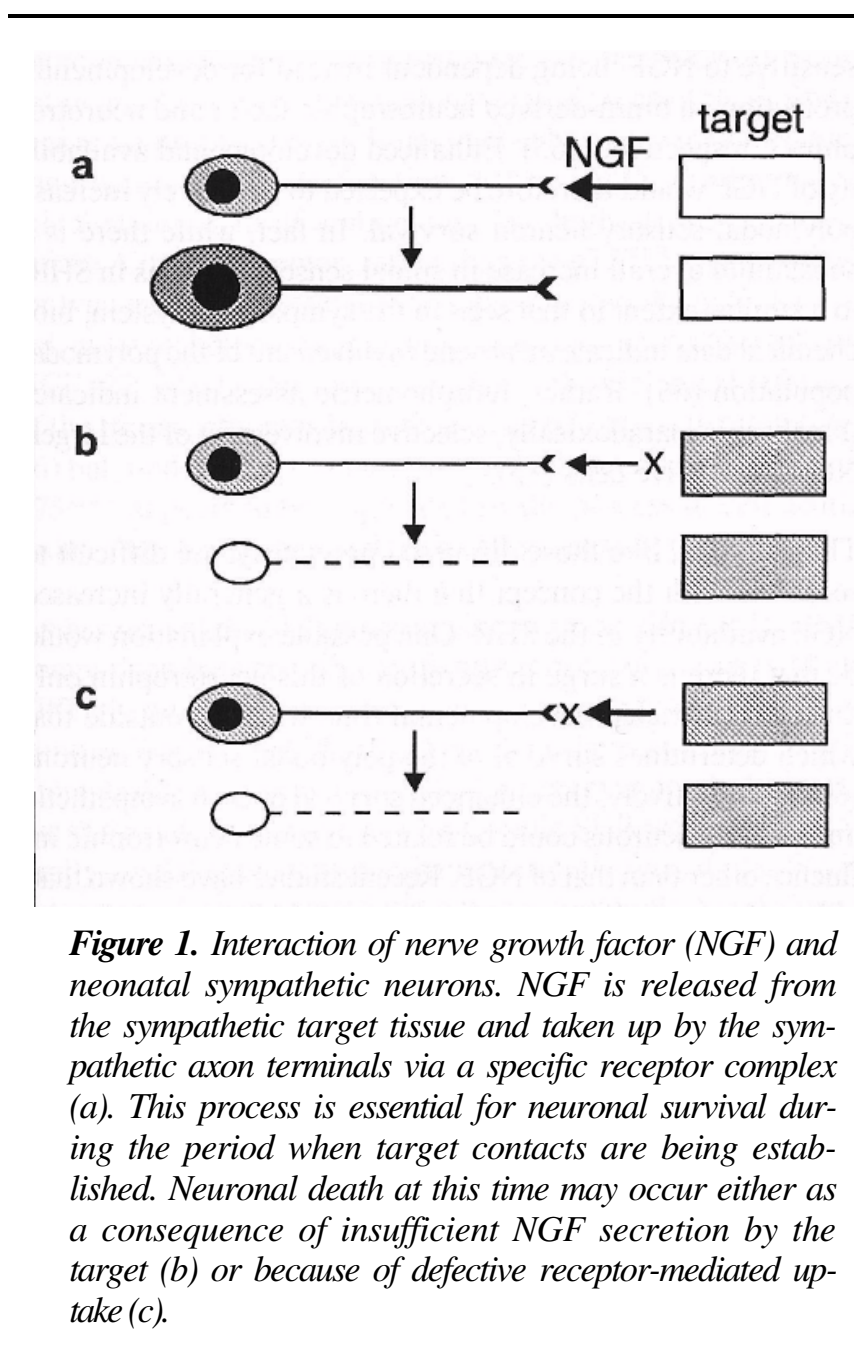

stances. Stimulated NGF secretion seems to involve the protein kinase $\mathrm{C}$ (PKC) pathway, as acute application of phorbol ester increases secretion while downregulation of PKC with maintained phorbol ester application inhibits secretion. Secretion is also inhibited by the cyclic AMP/protein kinase A (PKA) system (34). These second messenger pathways appear to be disturbed in the SHR. Both downregulation of PKC and activation of PKA increase basal NGF secretion, while there is no effect on secretion from WKY rat cells (34). Similarly, application of a purinoceptor agonist stimulates NGF secretion from SHR, but not WKY rat cells (29).

- What is the stimulant for excessive NGF secretion in vivo?

Undoubtedly, the capacity of a tissue to produce NGF would be expected to be proportional to its bulk. Therefore, the fact that hypertension is accompanied by vascular medial overgrowth could be a contributory factor (35). Traditionally, the vascular hypertrophy and hyperplasia associated with genetic hypertension has been assumed to be a response to the elevated transmural tension resulting from blood pressure elevation (36). However, several studies have shown that dissociation of these parameters is possible. Thus, doses of angiotensin II (All) blockers or angiotensin-converting enzyme (ACE) inhibitors which produce only moderate reduction in blood pressure can completely prevent vascular changes $(37,38)$. Reduced arterial wall thickness was also seen after ACE inhibitor treatment in renal-clip hypertensive rats, although no reduction in blood pressure occurred, and in normotensive rats (39). In addition, crossbreeding experiments using SHR- and WKY rat-related substrains have demonstrated that vascular hypertrophy is possible without blood pressure elevation (17).

Turtle's studies $(29,34)$ mentioned previously indicate that SHR arterial SMC, at least under in vitro conditions, secrete excessive amounts of NGF in response to sympathomimetics and to stimuli which are known to be causally implicated in SMC growth. Such a situation would therefore be compatible with the possibility of a positive feedback loop, whereby increased sympathetic traffic and increased blood pressure would induce progressively more arterial wall growth and a progressively denser sympathetic innervation (29). On the other hand, studies of age-related changes in tissue catecholamines indicate that the sympathetic hyperinnervation is if anything denser, relative to vessel mass, soon after birth than it is in adult SHR animals (40). Furthermore, local surgical denervation of a SHR artery early in life does not reduce overgrowth of the vessel wall as hypertension develops (41). These observations would not seem to favor the concept of a positive feedback loop relating sympathetic input, vessel growth and NGF availability.

Renal cross-transplantation between WKY rats and SHR showed that recipients of SHR kidneys develop hypertension even when the donors have been maintained normotensive throughout life (42-44). This suggests a role for some renal factor(s) in generating elevated blood pressure and chronic interference with All production or action early in life is well documented to cause persistent reduction of SHR blood pressure to close to normal values (45-50). Angiotensin II is known to stimulate protein synthesis and to be mitogenic in cultured vascular SMC $(51,52)$ and to enhance NGF gene expression in the same preparation (25). Furthermore, All has a greater stimulant effect on growth of cultured vascular SMC from SHR than those from WKY rats (53), aortic SMC and fibroblasts from SHR show elevated rates of proliferation compared with WKY rats (54) and some, but not all^ studies have found elevated plasma renin or All in young SHR $(55,56)$. Additional evidence for an influence of All on NGF gene expression comes from studies showing that chronic administration of All to young WKY rats elevated vascular NGF to levels similar to those found in SHR, while administration of All receptor an- 
tagonists to young SHR reduced vascular NGF to the levels found in WKY rats (31).

Despite this abundant evidence for a causal link between All, arterial mitogenesis, NGF availability and sympathetic overgrowth, however, several lines of evidence suggest that the situation is more complex than it appears at first. First comes the increased catecholamine spillover restricted to certain regional vascular beds in SHR (12). Notably, spillover is not elevated in skeletal muscle, despite the fact that its bed constitutes a major site of ongoing sympathetic discharge related to maintenance of total peripheral resistance. This finding argues against generalized sympathetic overgrowth and, therefore, against generalized overproduction of NGF; and is consistent with biochemical findings that tissue $\mathrm{mRNA}^{\mathrm{NaF}}$ and sympathetic innervation density are not uniformly elevated in all sympathetic target tissues $(19,29,57)$. It is difficult, therefore, to see how either NGF oversecretion or sympathetic nerve overgrowth in this situation can be secondary to the effect of a circulating mitogen such as AIL The alternative of tissue All acting as a local mitogen within SHR vascular tissues is similarly made unlikely by the apparent absence of elevated tissue peptide levels (56).

As well, while cross-suckling of SHR pups on WKY dams results in lowered blood pressure, suckling WKY pups on SHR dams does not induce hypertension (58), once again indicating that even if circulating molecule(s) are causally involved, additional factors are also vital. In addition, the blood pressure reduction caused by ACE inhibition is reversed by simultaneous administration of aldosterone or salt and this reversal induces arterial wall growth in proportion to the degree to which blood pressure rises (47). These data suggest that the role of All in establishment of hypertension in the SHR may be through effects on sodium balance and that the arterial overgrowth is, after all, secondary to blood pressure elevation rather than to a specific action of AIL This conclusion is also consistent with recent evidence that the extent of vessel wall regression is similar following hypotensive treatment with calcium channel blockers as it is with All receptor antagonists (59).

\section{•• Abnormalities of spinal sensory development}

The spinal sensory neurons originate, as do the sympathetic ganglionic neurons, from neuroblasts of the neural crest and some of them depend, as do the sympathetics, on NGF for protection from developmental cell death. This NGF-dependent sensory population comprises the small-diameter neurons with nonmyelinated axons that transduce nociceptive information and which, in many cases, contain one or both of the neuropeptides substance P (SP) and calcitonin gene-related peptide (6064). By contrast, the larger spinal sensory neurons which transduce mechanoceptive and proprioceptive information are in- sensitive to NGF, being dependent instead for developmental protection on brain-derived neurotrophic factor and neurotrophin-3, respectively (65). Enhanced developmental availability of NGF would therefore be expected to selectively increase polymodal sensory neuron survival. In fact, while there is a substantial overall increase in spinal sensory neurons in SHR, to a similar extent to that seen in the sympathetic system, biochemical data indicate an absend involvement of the polymodal population (66). Rather, morphometric assessment indicates that there is, paradoxically, selective involvement of the larger, NGF-insensitive cells (15).

These results, like those discussed previously, are difficult to reconcile with the concept that there is a generally increased NGF availability in the SHR. One possible explanation would be that there is a surge in secretion of this neurotrophin only during a restricted developmental time window, outside that which determines survival of the polymodal sensory neurons (66). Alternatively, the enhanced survival of both sympathetic and sensory neurons could be related to some neurotrophic influence other than that of NGF. Recent studies have shown that, although sympathetic neurons depend entirely on NGF for survival during late development, they depend at an earlier developmental stage on neurotrophin-3 and/or brain-derived neurotrophic factor (67). Enhanced availability of one of these neurotrophins in utero might therefore lead both to direct protection of large sensory neurons from developmental cell death and to more rapid maturation and hence better viability of sympathetic neurons.

\section{- Interpretation in the context of hypertension}

Even if the causal relationship between All, NGF and sympathetic overactivity were to be verified, the link to hypertension still remains obscure. A variety of evidence suggests that abnormalities external to this axis may be implicated in blood pressure elevation. As well as the data mentioned previously, arguing an essential role of disordered sodium balance (47), chronic treatment of young SHR with a vasopressin antagonist has been reported to produce effects that were closely similar to those seen with ACE inhibitors or All receptor antagonists, with substantial attenuation of hypertension which was sustained after cessation of treatment (68).

Genetic studies have shown that the NGF gene cosegregates with the inheritance of hypertension $(32,69)$ and that it lies close to other loci on chromosome 10 that are associated with blood pressure regulation, including the gene for ACE (70). On the other hand, there appears to be no cosegregation of the NGF gene and the vascular hypertrophy that accompanies hypertension $(71)$. Nemoto and colleagues $(31,69)$ have also reported a structural abnormality in the signal peptide of the low-affinity NGF receptor $\left(\mathrm{p} 75^{\mathrm{NOFR}}\right)$ in SHR. This abnormality has been 
found to cosegregate with hypertension in one study (69), but not in another (72). The functional significance of these findings remains uncertain. It is not known how the signal peptide abnormality affects the function of the $\mathrm{p} 75^{\mathrm{NGFR}}$. Furthermore, this function is itself ambiguous. The high-affinity tyrosine kinase A (trkA) receptor, rather than the $\mathrm{p} 75^{\mathrm{NOFR}}$, is the receptor type which is essential for NGF entry into the axon terminal and which, therefore, mediates the neuroprotective role of NGF $(22,73)$. Under some conditions, the biological efficacy of the trk receptor may be enhanced by $\mathrm{p} 75^{\mathrm{NGFR}}$ activation (7476) but, under other circumstances, the functional presence of $\mathrm{p} 75^{\mathrm{NGFR}}$ appears to be implicated in the process of cell death rather than being involved with cell protection $(76,77)$.

Assessment of the SHR literature is complicated by the fact that comparison between data from different laboratories is often difficult, due to uncertainties concerning the properties of the control WKY rats $(78,79)$. This is perhaps inevitable with animals that have been bred in many sites over nearly 40 years, but is accentuated by the fact that, while SHR were made generally available only after having been fully inbred, the WKY rats were released before inbreeding was complete; a decision which led to WKY stocks possessing at least two quite different genotypes (80). A further level of complexity resulting from this variability has been the introduction of other normotensive strains, for example the Sprague Dawley and the DonRyu inbred Wistar rats, as controls for the SHR. While these strains may be appropriate controls for particular experiments, it would be a considerable leap of faith to assume that they uniformly share similar differences with the SHR, those which have been documented previously for the WKY rats.

Sympathetic overgrowth per se is hardly likely to elevate vasomotor tone and hence elevate peripheral resistance, because under normal circumstances the baroreceptor reflexes restore homeostasis. If verification of this was needed, it comes from experiments utilizing NGF treatment of normotensive animals, which have demonstrated that massive sympathetic overgrowth is not accompanied by altered blood pressure $(81,82)$. Hence, whatever distortions of events influencing sympathetic maintenance of peripheral resistance are invoked, these can lead to hypertension only where the central nervous system pathways that control blood pressure are also disrupted. This central disruption, therefore, inevitably becomes the crucial etiological factor. The brain of the SHR possesses a variety of quantitative neurochemical differences to that of the WKY rat (83), but it is not clear how these differences relate to the state of hypertension: some may be a consequence of elevated blood pressure and some may relate to the behavioral abnormalities exhibited by the SHR, which are not genetically linked to hypertension (20). In this context, it is of interest that transplantation of embryonic SHR hypothalamic neurons into the hypothalami of WKY rats causes permanent elevation of blood pressure, while there was no effect on blood pressure when WKY rat neurons were transplanted into WKY rat hypothalami (84). In the absence of further information about the circuitry involved, however, it is impossible to interpret these results properly.

\section{PROPERTIES OF THE GENETICALLY HYPERTENSIVE RATS}

\section{- Many characteristics of the genetically hypertensive rats differ from those of the spontaneously hypertensive rats}

As with the SHR, hypertension in the GH rat appears at the latest within a few days after birth, progressing to reach a plateau by around age of 12 weeks $(85,86)$. In many other characteristics, however, the $\mathrm{GH}$ rat is strikingly differs from the SHR. Cultured vascular SMC show similar rates of division for GH and its control (N) strain, by contrast with the elevated replication rate in SHR vs WKY rats, although stimulation of thymidine incorporation by All is elevated in GH rats (87-89). Vascular SMC content of free ionized calcium is elevated in SHR but normal in GH rats (90). While sodium influx into SHR red blood cells is greater than in WKY ones, there is no difference between GH and N erythrocytes (91). Furthermore, salt absorption from the intestine rises with age in SHR but remains constant in GH rats (85) and SHR but not GH rats show preference for high salt intakes, which is reflected in higher total body levels of sodium and $24 \mathrm{hr}$ exchangeable sodium in SHR vs WKY rats but not in GH vs $\mathrm{N}(85,92,93)$.

\section{- $\quad$ Peripheral nervous system abnormalities}

\section{Abnormal sympathetic cell death}

Although vascular overgrowth is similar in both GH and SHR, the relationship between this phenomenon and the sympathetic nervous system is quite different for each strain. While the numbers of sympathetic neurons are increased in SHR, those in GH rats are by approximately $25 \%$ less than those in the normotensive controls (94). Furthermore, while NPY-positive and NPY-negative neurons are increased to equal proportions in $\mathrm{SHR}$, the reduction seen in GH rats is specific for NPY-containing cells (94). As these cells constitute about half the total sympathetic pool, there is of the order of $50 \%$ reduction of NPY-positive neurons in adult GH animals. At birth, sympathetic cell numbers are similar in $\mathrm{GH}$ and $\mathrm{N}$ pups, the difference appearing over the time of developmental cell death between 3-14 days postnatally (95). Thus, as with the SHR, the difference in neuron numbers is due to an abnormal degree of cell death rather than to abnormal production of sympathetic neuroblasts, although while there is reduced death in SHR, the process is exaggerated in the $\mathrm{GH}$ rat. This could be due to reduced NGF availability over the cell death period (Fig.lb). Consistent with this, treatment of GH pups over the first post- 
natal week with doses of NGF that are insufficient to rescue dying cells in control animals restores GH neuron numbers to normal (61).

\section{- Abnormal spinal sensory cell death}

Sympathetic cell number reduction in GH rats is accompanied by augmented numbers of SP-containing spinal sensory neurons and concomitant increased peripheral innervation density by SP sensory axons (96-98). Like the exaggerated sympathetic cell death, the sensory overgrowth is prevented by neonatal NGF treatment, suggesting a common cause (61). Superficially, it may appear paradoxical that a reduction in NGF availability sufficient to prejudice sympathetic neuron survival would simultaneously increase survival of another NGF-sensitive population. Nevertheless, it is well-documented that experimental reduction of sympathetic neuron numbers early in life causes overgrowth of SP-positive sensory neurons $(60,63,64)$. This is probably due to the fact that the sympathetic neurons are normally more efficient in gaining access to the available NGF, so limiting sensory survival; when the density of sympathetic inputs is reduced, more NGF is made available to the sensory population (Fig. 2). The finding of reduced sympathetic and increased sensory survival in $\mathrm{GH}$ rats seems most likely to reflect an analogous situation.

- Is nerve growth factor availability or utilization abnormal?

Resting NGF secretion by cultured GH rat vascular SMC is substantially lower than in cells from the control N strain (99), consistent with the possibility that the reduced sympathetic survival is related to reduced NGF availability. However, for this to result in exaggerated sensory neuron protection, developmental sensitivity to NGF would have to continue later for the sensory than for the sympathetic pool, so allowing a fall in competition from the sympathetics while the sensors are still able to respond to the protective influence of NGF. From what is known of the time courses of developmental cell death in neural crest-derived systems, the window for spinal sensory death appears to be if anything earlier than that for the sympathetics, so this scenario is not entirely convincing. An alternative and perhaps more likely possibility is that the environmental NGF availability is normal, but that the sympathetic neurons cannot utilize it fully, perhaps because of reduced numbers of axonal trk receptors (Fig. Ic). The specificity of excessive death of the NPY-positive sympathetic phenotype could be interpreted as also favoring an abnormality of neuronal function rather than of NGF production. However, as NPY-containing cells are predominantly small (100) and therefore have small-diameter axons, they may be less efficient at transporting NGF and hence more susceptible to altered NGF availability, regardless of whether this were due to a neuronal or an extraneuronal lesion.

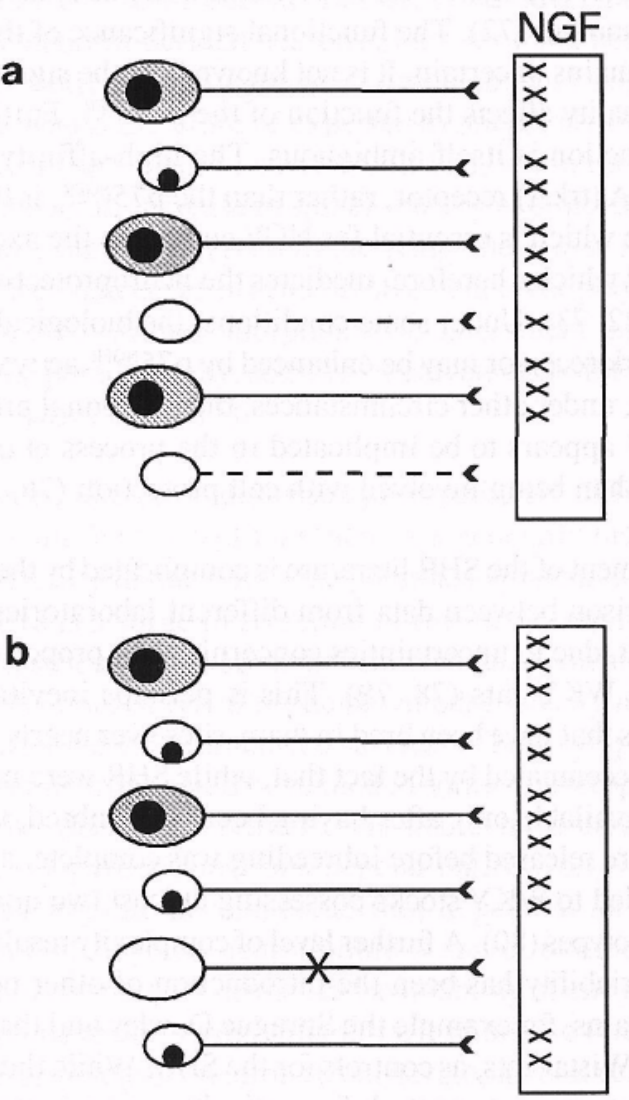

Figure 2. Consequences of competition for limited access to nerve growth factor (NGF) between developing sympathetic and spinal sensory neurons, in which the sympathetic neurons are more efficient. In this scheme, a sample of three sympathetic (large) and three sensory (small) neurons are competingfor 12 NGF access sites. In order to survive, each sympathetic neuron requires three and each sensory neuron requires two of these sites. Under normal conditions (a), two of the three sensory neurons die because of lack of NGF availability. If, however, only one of the three sympathetic neurons is removed (b), then sufficient NGF access sites are freed to allow all sensory neurons to survive.

\section{- Interpretation in the context of hypertension}

As with the SHR, the question must be asked whether the neural abnormalities seen in the GH rat bear any causal relationship to development of hypertension. Tissue catecholamine turnover studies (101) and studies of neuronal tyrosine hydroxylase activity under normal conditions and following decentralization (16) suggest that sympathetic drive is similar in $\mathrm{GH}$ to that in the normotensive control strain. Relative to the absolute level of blood pressure, therefore, this implies that 
there is sympathetic overactivity . One factor in this could be the overgrowth of SP-positive sensory neurons. The overgrowth includes massive proliferation of SP terminal axons around sympathetic motoneurons (96) and, as SP is known to cause long-lasting depolarization of these cells (102), this might constitute a basis for enhancement of sympathetic ganglionic transmission (96). Although the functional wiring of this system is uncertain, it is pertinent to note that neonatal destruction of the peripheral SP neurons with capsaicin in normotensive animals has been found to result in resting hypotension and impaired baroreflex responses (103), implying some positive role for these sensory inputs in ongoing neural control of peripheral resistance. Data are not available to indicate whether the central nervous system pathways mediating cardiovascular control are normal in GH rats (85).

Vascular SMC of GH rats appear not to exhibit the generally increased responsiveness to mitogenic stimuli that is typical of the SHR. In cell culture, however, they do exhibit a heightened growth response to All (85). In view of the possibility that All is causally linked to vascular SMC production of NGF (see discussion above in relation to the SHR) it would be of considerable interest to measure NGF secretion from GH rat arterial SMC. As the NGF-dependent reduction in sympathetic neurons may be due to a neuronal receptor defect, there is no longer any reason to presume that NGF production is decreased in this strain. Indeed, it is quite possible that, as in SHR, there is increased NGF production in GH vasculature and that this, as well as reduced competition from sympathetics, contributes to the overgrowth seen in the sensory polymodal neurons. However, there is no evidence at present to either support or refute such a possibility. As with the SHR, chronic ACE inhibition or All receptor blockade in young $\mathrm{GH}$ animals produces longlasting attenuation of hypertension and reduction of arterial wall growth $(104,105)$ but, once again as with the SHR, chronic calcium receptor antagonist treatment causing similar blood pressure reduction also has a similar effect on wall bulk (104, 105). This suggests that the effects of interfering with the angiotensin pathway may be due to the effect on blood pressure rather than to any specific etiological involvement of AIL It is also worth noting that crossbreeding studies indicate that, by contrast with the situation in the SHR, the ACE allele does not cosegregate with blood pressure in the GH rat (106).

Paradoxically, the excessive perinatal death of sympathetic vasomotor neurons in the GH rat might also contribute to its hypertensive condition. Removal of sympathetic innervation has been shown to lead to hyperplasia and hypertrophy (107109 ) and increased collagen production (110) in a number of smooth muscle tissues, suggesting that these nerves normally exert a restraining effect on muscle growth (111). It is therefore possible that the reduced sympathetic innervation density could be a factor in stimulating vascular wall growth in the young GH rat, so helping to enhance peripheral resistance and blood pressure.

\section{CONCLUSIONS}

The neurotrophic abnormalities which have been shown in SHR and GH rats may be important from two aspects. First, they may help elucidate a coherent mechanistic sequence by which blood pressure becomes elevated in these strains and, perhaps, in hypertensive patients. Certainly, the extensive analysis of other properties of these animals over 30 years has not advanced our understanding of essential hypertension to nearly the extent that had been hoped. Indeed, the current state of the field suggests that the abnormalities which have been most highlighted as potentially important in the rat may bear little relation to the clinical situation. For example, Harrap and coworkers found that, in contrast to the association seen in SHR, there was no evidence for coinheritance of the gene for ACE with a predisposition for hypertension in a Caucasian population (112). Investigation of novel aspects of developmental biology may therefore offer an essential reprieve for the status of the genetically hypertensive rat as a model for human disease.

Even if no definitive mechanistic insights into hypertension are forthcoming, these animals provide two interesting situations in which there is disruption of the normal endogenous neurotrophic systems during development. As such, they offer a valuable adjunct to other ways of manipulating neurotrophic effects, such as by gene deletion. In particular, they may throw light on hitherto undocumented roles of specific neurotrophins. In this regard, and bearing in mind recent documentation of the variety of novel effects of NGF in non-neural areas, such as the immune system $(23,113-120)$ it will be important to reexamine the possible links between neurotrophin abnormalities and the multiplicity of tissue abnormalities that have been reported for the SHR and GH rats. These include altered ionic fluxes across the membranes of a number of cell types (91, 121-123) and the defective coupling of renal tubular dopamine receptors to second messenger systems (124). So far, these defects have been regarded only in relation to their putative involvement in genesis of hypertension. Now, however, they are known to exist in an animal known to also possess a neurotrophic abnormality. It is possible that further analyses will lead to recognition of hitherto unsuspected roles for endogenous NGF in normal development.

\section{REFERENCES}

1. Lovenberg W, Horan M. Genetic rat models for hypertension: Guidelines for breeding, care and use. Hypertension 1987; 9 (Suppl I): 1-42 
2. Smirk FH, Hall WH. Inherited hypertension in rats. $\mathrm{Na}$ ture $1958 ; 182: 727-728$

3. Phelan EL. The New Zealand strain of rats with genetic hypertension. NZMedJ 1968; 67: 334-344

4. Phelan EL, Clark DWJ, Gresson CR, Jones DR. The development and inheritance of the high blood pressure in the New Zealand strain of rats with genetic hypertension. In: Okamoto K, editor. Spontaneous Hypertension: Its Pathogenesis and Complications. Tokyo, Igaku Shoin, 1972; 18-22

5. Okamoto K, Aoki K. Development of a strain of spontaneously hypertensive rats. Jap CircJ 1963; 27: 282-293

6. Tanase H, Suzuki Y, Ooshima A, Yamori Y, Okamoto K. Further genetic analysis of blood pressure in spontaneously hypertensive rats. In: Okamoto K, editor. Spontaneous Hypertension: Its Pathogenesis and Complications. Tokyo, Igaku Shoin, 1972; 9-12

7. Okamoto K, Yamori Y, Ooshima A, Park C, Haebara H, Matsumoto $\mathrm{M}$ et al. Establishment of the inbred strain of the spontaneously hypertensive rat and genetic factors involved in hypertension. In: Okamoto K, editor. Spontaneous Hypertension: Its Pathogenesis and Complications. Tokyo, Igaku Shoin, 1972; 1-8

8. Iriuchijma J. Sympathetic discharge rate in spontaneously hypertensive rats. Jap Heart J 1973; 14: 350-356

9. Judy WV, Watanabe AM, Henry DP, Besch HR Jr, Murphy WR, Hockel GM. Sympathetic nerve activity: role in regulation of blood pressure in the spontaneously hyper-

', tensive rat. Circ Res 1976; 38 (Suppl II): 21-29

10. Thoren P. Efferent renal nerve traffic in the spontaneously hypertensive rat. Clin Exp Hypertens [A] 1987; 9 (Suppl I): $259-280$

11. DiBona GF, Jones SY, Sawin LL. Renal sympathetic neural mechanisms as intermediate phenotype in spontaneously hypertensive rats. Hypertension 1996: 27: 626-630

12. Adams MA, Bobik A, Korner PL Differential development of vascular and cardiac hypertrophy in genetic hypertension: relation to sympathetic function. Hypertension 1989; 14: 191-202

13. Nakamura K, Gerold M, Thoenen H. Genetically hypertensive rats: Relationship between the development of hypertension and the changes in norepinephrine turnover of peripheral and central adrenergic neurons. Arch Pharmacol 1971; 271: 157-169

14. Messina A, Sullivan J, Bell C. Sympathetic neuron numbers and NPY content in SHR [abstract]. / Hypertens 1992; 10 (Suppl 4): S8

15. Messina A, Bakhle YS, Bertram JF, Bell C. Decreased developmental cell death in sympathetic and spinal sensory nervous systems of the Kyoto spontaneously hypertensive rat. J Hypertens 1996, In press

16. Gurusinghe CJ, Harris PJ, Abbott DF, Messina A, Bell C. Quantitation of tyrosine hydroxylase and neuropeptide $\mathrm{Y}$ immunoreactivity in single rat sympathetic neurons: effects of preganglionic nerve activity. JNeurosciRes 1991; 29: $68-75$

17. Fan XM, Hendley ED, Forehand CJ. Enhanced vascular neuropeptide Y-immunoreactive innervation in two hypertensive rat strains. Hypertension 1995; 26: 758-763

18. Howes LG, Summers RJ, Louis WJ. The influence of age and sex on cardiac, renal and caudal artery catecholamine content in spontaneously hypertensive (SHR) and Wistar-Kyoto (WKY) rats. JAuton Pharmacol 1986; 6: $171-180$

19. Head RJ, Cassis LA, Robinson RW, Westfall DP, Stitzel RE. Altered catecholamine contents in vascular and nonvascular tissues in genetically hypertensive rats. Blood Vessels 1985; 22: 196-204

20. Peruzzi D, Hendley ED, Forehand CJ. Hypertrophy of stellate ganglion cells in hypertensive, but not hyperactive, rats. Am J Physiol 1991; 261: R979-R984

21. Oppenheim RW. Cell death during development of the nervous system. Anпи Rev Neurosci 1991; 14: 453-502

22. Arumae U. Neurotropins: neural antiapoptotic molecules with neurite growth-promoting properties. Biomed Rev 1995; 4 : $15-28$

23. Levi-Montalcini R, Skaper SD, Dal Toso R, Petrelli L, Leon A. Nerve growth factor: from neurotrophin to neurokine. Trends Neurosci 1996; 19: 514-520

24. Thoenen H. Neurotrophins and neuronal plasticity. Science 1995; 270: 593-598

25. Creedon D, Turtle JB. Nerve growth factor synthesis in vascular smooth muscle. Hypertension 1991; 18:730-741 
26. Ueyama T, Hamada M, Hano T, Nishio I, Masuyama Y, Furukawa S. Increased nerve growth factor levels in spontaneously hypertensive rats. / Hypertens 1992; 10: 215219

27. Falckh PH, Harkin LA, Head RJ. Resistance vessel gene expression of nerve growth factor is elevated in young spontaneously hypertensive rats. J Hypertens 1992; 10: 913-918

28. Zettler C, Rush RA. Elevated concentrations of nerve growth factor in heart and mesenteric arteries of spontaneously hypertensive rats. Brain Res 1993; 614: 15-20

29. Spitsbergen JM, Stewart JS, Turtle JB. Altered regulation of nerve growth factor secretion by cultured VSMCs from hypertensive rats. AmJPhysiol 1995; 269: H621-H628

30. Donohue SJ, Head RJ, Stitzel RE. Elevated nerve growth factor levels in young spontaneously hypertensive rats. $\mathrm{Hy}$ pertension 1989; 14: 421-426

31. Nemoto K, Kageyama H, Hagiwara T, Tashiro F, Tomita $\mathrm{T}$, Tomita I et al. Mutation of low affinity nerve growth factor receptor gene in spontaneously hypertensive and stroke-prone spontaneously hypertensive rats: one of the promising candidate genes for hypertension. Brain Res 1994; 655: 267-270

32. Kapuscinski M, Charchar F, Innes B, Mitchell GA, Norman TL, Harrap SB. Nerve growth factor gene and hypertension in spontaneously hypertensive rats. $J$ Hypertens 1996; 14: 191-197

33. Ueyama T, Hamada M, Hano T, Nishio I, Masuyama Y, Furukawa S. Production of nerve growth factor by cultured vascular smooth muscle cells from spontaneously

I,-... hypertensive and Wistar-Kyoto rats. J Hypertens 1993;

$\mathrm{JH} \ll \quad$ 11: 1061-1065

34. Turtle JB, Spitsbergen JM, Stewart JS, McCarty RM, Steers WD. Altered signaling in vascular smooth muscle from spontaneously hypertensive rats may link medial hypertrophy, vessel hyperinnervation and elevated nerve growth factor [abstract]. Clin Exp Pharmacol Physiol 1994; (Suppl 1): S43

35. HeadRJ. Hypernoradrenergic innervation: its relationship to functional and hyperplastic changes in the vasculature of the spontaneously hypertensive rat. Blood Vessels 1989; 26:1-20
36. Folkow B. Physiological aspects of primary hypertension. PhysiolRev 1982; 62: 347-504

37. Rizzoni D, Castellano M, Porteri E, Bettoni G, Muiesan ML, Cinelli A et al. Effects of low and high doses of fosinopril on the structure and function of resistance arteries. Hypertension 1995; 26: 118-123

38. Owens GK. Influence of blood pressure on development of aortic medial smooth muscle hypertrophy in spontaneously hypertensive rats. Hypertension 1987; 9: 178-187

39. Wang D-H, Prewitt RL. Captopril reduces aortic and microvascular growth in hypertensive and normotensive rats. Hypertension 1990; 15: 68-77

40. Donohue S J, Stitzel RE, Head RJ. Time course of changes in the norepinephrine content of tissues from spontaneously hypertensive and Wistar Kyoto rats. / Pharmacol ExpTher 1988; 245: 24-31

41. Todd ME, Bevan RD. Effects of postnatal growth and denervation on characteristics of the saphenous artery in SHR and WKY rats between 3 and 6 weeks of age: an in vitro study. Can J Physiol Pharmacol 1991; 69: 731-738

42. Rettig R, Folberth C, Stauss H, Kopf D, Waldherr R, Unger T. Role of the kidney in primary hypertension: a renal transplantation study in rats. Am J Physiol 1990; 258:F606-F611

43. Harrap SB, Wang BZ, MacLellan DG. Transplantation studies of the role of the kidney in long term blood pressure reduction following brief ACE inhibitor treatment in young spontaneously hypertensive rats. Clin Exp Pharmacol Physiol 1994; 21: 129-131

44. Harrap SB, Wang BZ, MacLellan DG. Renal transplantation between male and female spontaneously hypertensive rats. Hypertension 1992; 15: 431-434

45. Harrap SB, Van der Merwe WM Griffin SA, MacPherson F, Lever AF. Brief angiotensin converting enzyme inhibitor treatment in young spontaneously hypertensive rats reduces blood pressure long-term. Hypertension 1990; 16: 603-614

46. Korner PI, Bobik A. Cardiovascular development after enalopril in spontaneously hypertensive and Wistar-Kyoto rats. Hypertension 1995; 25: 610-619 
47. Harrap SB, Mitchell GA, Casley DJ, Mirakian C, Doyle AE. Angiotensin II, sodium, and cardiovascular hypertrophy in spontaneously hypertensive rats. Hypertension 1993; $21: 50-55$

48. Morton JJ, Beattie EC, MacPherson F. Angiotensin II receptor antagonist losartan has persistent effect on blood pressure in young spontaneously hypertensive rats: lack of relation to vascular structure. / Vase Res 1992; 29:264268

49. Thybo NK, Korsgaard N, Eriksen S, Christensen KL, Mulvany MI Dose-dependent effects of perindopril on blood pressure and small-artery structure. Hypertension 1994; 23: 659-666

50. Wielbo D, Simon A, Phillips MI, Toffolo S. Inhibition of hypertension by peripheral administration of antisense oligodeoxynucleotides. Hypertension 1996; 28: 147-151

51. Berk BC, Vekshtein V, Gordon HM, Tsuda T. Angiotensin II-stimulated protein synthesis in cultured vascular smooth muscle cells. Hypertension 1989; 13: 305-314

52. Lyall F, Morton JJ, Lever AF, Cragoe EJ. Angiotensin II activates $\mathrm{Na}^{\wedge}-\mathrm{tP}$ exchange and stimulates growth in cultured vascular smooth muscle cells. J Hypertens 1988; 6 (Supp14):S438-S441

53. Bunkenburg B, van Amelsvoorst T, Rogg H, Wood JM. Receptor-mediated effects of angiotensin II on growth of vascular smooth muscle cells from spontaneously hypertensive rats. Hypertension 1992; 20: 746-754

54. Battle T, Arnal J-F, Michel J-B. Hyperproliferation of aortic smooth muscle cells and fibroblasts from young SHR rats is not shared by endothelial cells. Clin Exp Pharmacol Physiol 1994; 21: 981-989

55. Morton JJ, Beattie EC, Griffin SA, MacPherson F, Lyall F, Russo D. Vascular hypertrophy, renin and blood pressure in the young spontaneously hypertensive rat. Clin Sci 1990; 79: 523-530

56. Campbell DJ, Duncan A-M, Kladis A, Harrap SB. Angiotensin peptides in spontaneously hypertensive and normotensive Donryu rats. Hypertension 1995: 25: 928-934

57. Falckh PH, Harkin LA, Head RJ. Nerve growth factor mRNA content parallels altered sympathetic innervation in the spontaneously hypertensive rat. Clin Exp Pharmacol Physiol 1992; 19: 541-545
58. McCarty R, Lee JH. Maternal influences on adult blood pressure of SHRs: a single pup cross-fostering study. PhysiolBehav 1996; 59: 71-75

59. Li J-S, Turgeon A, Schiffrin EL. Effect of angiotensin converting enzyme inhibition or calcium channel blockade on small coronary and renal arteries of SHR [abstract]. JHypertens 1996; 14 (Suppl 1): S86

60. Kessler JJ, Bell WO, Black IB. Interactions between the sympathetic and sensory innervation of the iris. JNeurosci 1983; 3: 1301-1307

61. Messina A, Bell C. Are genetically hypertensive rats deficient in nerve growth factor? NeuroReport 1991; 2: 4548

62. Hendry IA, Messina A, Bell C. Neonatal nerve growth factor treatment alters the preganglionic innervation pattern of rat superior cervical ganglion. Neurosci Lett 1993; 148: $117-120$

63. Yodlowski ML, Fredieu JR, Landis SC. Neonatal 6hydroxydopamine treatment eliminates cholinergic sympathetic innervation and induces sensory sprouting in rat sweat gland. JNeurosci 1984; 4: 1535-1548

64. Hill CE, Jenilek H, Hendry IA, McLennan IS, Rush RA. Destruction by anti-NGF of autonomic, sudomotor neurons and subsequent hyperinnervation of the foot pad by sensory fibres. JNeurosci Res 1988; 19: 474-482

65. Mu X, Silos-Santiago I, Carroll SL, Snider WD. Neurotrophin receptor genes are expressed in distinct patterns in developing dorsal root ganglia. J Neurosci 1993; 13: 4029-4041

66. Messina A, Bakhle YS, Bell C. Spinal sensory neuron numbers in the spontaneously hypertensive rat (SHR) [abstract]. JPhysiol 1995; 489: 7P-8P

67. Verdi JM, Anderson DJ. Neurotrophins regulate sequential changes in neurotrophin receptor expression by sympathetic neuroblasts. Neuron 1994; 13: 1359-1372

68. Burrell LM, Phillips PA, Risvanis J, Aldred KL, Hutchins AM, Johnston CI. Attenuation of genetic hypertension after short-term vasopressin VIA receptor antagonism. Hypertension 1995; 26: 828-834

69. Nemoto K, Kageyama H, Ueyama T, Fukamachi K, Sekimoto M, Tomita I et al. Mutation of low affinity nerve 
growth factor receptor gene is associated with the hypertensive phenotype in spontaneously hypertensive inbred rat strains. Neurosci Lett 1996; 210: 69-72

70. Hilbert P, Lindpaintner K, Beckmann JS, Serikawa T, Soubrier F, Dubay C et al. Chromosomal mapping of two genetic loci associated with blood pressure regualtion in hereditary hypertensive rats. Nature 1991; 353: 521-529

71. Kapuscinki M, Mitchell GA, Charchar F, Harrap SB. Genetic analysis of nerve growth factor gene, cardiovascular hypertrophy and high blood pressure in SHR [abstract]. Clin Exp Pharmacol Physiol 1994; Suppl. 1: S45

72. Kapuscinski MK, Nemoto K, Ueyama T, Charchar F, Kageyama H, Fukumachi K et al. Low affinity nerve growth factor receptor gene co-segregates with decreased body weight and increased left ventricular weight in spontaneously hypertensive rats. Clin Exp Pharmacol Physiol 1996; 23: 614-616

73. Kaplan DR, Hempstead B, Martin-Zanca D, Chao M, Parada LF. The trk proto-oncogene product: a signal transducing receptor for nerve growth factor. Science 1991; 252: $554-558$

74. Lee K-F, Davies AM, Jaenisch R. p75-deficient embryonic dorsal root sensory and neonatal sympathetic neurons display a decreased sensitivity to NGF. Development 1994; 120: 1027-1033

75. Koide T, Takahashi JB, Hoshimaru M, Kojima M, Otsuka $\mathrm{T}$, Asahi $\mathrm{M}$ et al. Localization of trkB and low-affinity nerve growth factor receptor mRNA in the developing rat retina. Neurosci Lett 1995; 185: 183-186

76. Barrett GL, Bartlett PF. The p75 nerve growth factor receptor mediates survival or death depending on the stage of sensory neuron development. Proc Natl Acad Sci USA 1994; 91: 6501-6505

77. Rabizadeh $\mathrm{S}$, Bredesen DE. Is p75 ${ }^{\text {NGFR }}$ involved in developmental neural cell death? Dev Neurosci 1994; 16:207211

78. St Lezin E, Simonet L, Pravenec M, Kurtz TW. Hypertensive strains and normotensive 'control' strains: how closely are they related? Hypertension 1992; 19:419-424

79. Nabika T, Nara Y, Ikeda K, Endo J, Yamori Y. Genetic heterogeneity of the spontaneously hypertensive rat. $\mathrm{Hy}$ pertension 1991; 18: 12-16
80. Kurz TW, Morris RC. Biological variability in WistarKyoto rats: implications for research with the spontaneously hypertensive rat. Hypertension 1987; 10: 127-131

81. Zettler C, Head RJ, Rush RA. Chronic nerve growth factor treatment of normotensive rats. Brain Res 1991; 538: 251-262

82. Lee RMKW, Coughlin M, Tsoporis J, Kwan CY, Guan YY, Leenen FH. The effect of neonatal treatment of rats with nerve growth factor on the blood pressure and structure of the mesenteric arteries. Can J Physiol Pharmacol 1992; 70: 1154-1160

83. Versteeg DHG, Petty MA, Bohus B, De Jong W. The central nervous system and hypertension: the role of catecholamines and neuropeptides. In: GantenD, de Jong W, editors. Handbook of Hypertension, Vol. ^.Experimental and Genetic Models of Hypertension. Amsterdam: Elsevier, 1994; 395-440

84. Eilam R, Malach R, Bergmann F, Segal M. Hypertension induced by hypothalamic transplantation from genetically hypertensive to normotensive rats. J Neurosci 1991; 11: $401-411$

85. Simpson FO, Phelan EL, Ledingham JM, Millar JA. Hypertension in the genetically hypertensive $(\mathrm{GH})$ strain. In: GantenD, de Jong W, editors. Handbook of Hypertension. Vol 16. Experimental and Genetic Models of Hypertension. Amsterdam, Elsevier, 1994; 228-271

86. Kushinsky R, Bell C. Neural and non-neural components of the developing hypertension in genetically hypertensive rats. JAuton Nerv Syst 1983; 7: 141-148

87. Millar JA, Harris EL, Cassie NJ. Mitogenesis in cultured vascular smooth muscle cells from two rat models of hypertension in response to fetal calf serum and angiotensin II. J Cardiovasc Pharmacol 1990; 16 (Suppl 7): S14-S16

88. Hamada M, Harris EL, Millar JA, Simpson FO. Temporal differences in the cell cycles of cultured vascular smooth muscle cells from spontaneously hypertensive and normotensive Wistar-Kyoto rats. / VascMedBiol 1990; 2: $136-141$

89. Harris EL, Grigor MR, Millar JA. Differences in mitogenic responses to angiotensin II, calf serum and phorbol ester in vascular smooth muscle cells from two strains of genetically hypertensive rats. Biochem Biophys Res Commun 1990; 170: 1249-1255 
90. Hamada M, Miller JA, Ueyama T, Baba A, Phelan EL, Simpson FO et al. Different effects of angiotensin II on cytosolic free calcium concentration of two genetically hypertensive strains of rats [abstract]. JHypertens 1992; 10 (Suppl 4): S35

91. Wiley JS, Hutchinson JS, Mendelsohn FAO, Doyle AE. Increased sodium permeability of erythrocytes in spontaneously hypertensive rats. Clin Exp Pharmacol Physiol 1980; 7: 527-530

92. Simpson FO, Ledingham JM. Fluid intake, total exchangeable sodium and blood pressure in genetically hypertensive and normotensive rats on a sodium-free diet with a choice of saline and water. In: Rascher W, Clough D, GantenD, editors. Hypertensive Mechanisms. TheSpontaneously Hypertensive Rat as a Model to Study Human Hypertension. Stuttgart, Schattauer Verlag, 1982; 230233

93. Ledingham JM, Simpson FO, Hamada M. Salt appetite, body sodium, handling of a $\mathrm{NaCl}$ load, renin, and aldosterone in genetically and spontaneously hypertensive rats. JCardiovasc Pharmacol 1990; 16 (Suppl 7): S6-S8

94. Gurusinghe CJ, Harris PJ, Abbott D, Bell C. Neuropeptide $\mathrm{Y}$ in rat sympathetic neurons is altered by genetic hypertension and by age. Hypertension 1990; 16: 63-71

95. Messina A, Jaworowski A, Bell C. Detection of Jun but not Fos protein during developmental cell death in sympathetic neurons. / Comp Neural 1996, In press

96. Gurusinghe CJ, Bell C. Substance P immunoreactivity in the superior cervical ganglion of normotensive and genetically hypertensive rats. JAuton Nerv Syst 1989; 27: 249256

97. Gurusinghe CJ, Bell C. Different patterns of immunolocalization of calcitonin gene- related peptide and substance $\mathrm{P}$ in sympathetic ganglia of normotensive and genetically hypertensive rats. Neurosci Lett 1989; 106: 89-94

98. Bakhle YS, Bell C. Increased numbers of substance P-containing sensory neurons in a rat strain with a genetic neurotrophic defect. Neuropeptides 1994; 27: 169-174

99. Ueyama T, Hamada M, Hano T, Nishino I. Production of nerve growth factor in cultured vascular smooth muscle cells of genetically hypertensive rats [abstract]. Clin Exp Pharmacol Physiol 1994; (Suppl 1): S46
100. Messina A, Bell C. Morphometric and neurochemical changes in rat superior cervical ganglion during growth and adulthood. Mech Ageing Dev 1993; 67: 211-223

101. Phelan EL. Genetic and autonomic factors in inherited hypertension. CircRes 1970; 26/27 (Suppl II): 65-74

102. Holzer P. Local effector functions of capsaicin-sensitive sensory nerve endings: involvement of tachykinins, calcitonin gene-related peptide and other neuropeptides. Neuroscience 1988; 24:739-768

103. Donnerer J, Lembeck F. Autonomic reflexes in the rat are regulated by capsaicin-sensitive afferents [abstract]. Physiol 1989; 402: P69

104. Ledingham JM, Laverty R. Changes in structure of resistance arteries in the genetically hypertensive $(\mathrm{GH})$ rat after treatment with losartan or felodipine [abstract]. Hypertens 1996; 14 (Suppl 1): S87

105. Ledingham JM, Phelan EL, Cross MA, Laverty R. Effect of felodipine treatment and withdrawal on blood pressure and cardiovascular structure in New Zealand genetically hypertensive rats. Clin Exp Pharmacol Physiol 1995; (Suppl 1): S326-S328

106. Harris EL, Phelan EL, Thompson CM, Millar JA, Grigor MR. Heart mass and blood pressure have separate genetic determinants in the New Zealand genetically hypertensive (GH) rat. J Hypertens 1995; 13: 397-404

107. Campbell GR, Gibbins IL, Alien I, Gannon B. Effects of long-term denervation on smooth muscle of chick secondariorum. Cell Tissue Res 1977; 176: 143-156

108. Branco D, Albino-Teixeira A, Azevedo I, Osswald W. Structural and functional alterations caused at the extraneuronal level by sympathetic denervation of blood vessels. Arch Pharmacol 1984; 326: 302-312

109. Dimitriadou V, AubineauP, Taxi J, Seylaz J. Ultrastructural changes in the cerebral artery wall induced by longterm sympathetic denervation. Blood Vessels 1988; 25: 122-143

110. Fronek K. Trophic effects of the sympathetic nervous system on vascular smooth muscle. Ann BiomedEng 1983; 11:607-615

111. Bell C. Autonomic neurochemistry and risk factors during ageing. AttMed Interna 1990; 4: 273-294 
112. Harrap SB, Davidson HR, Connor JM, Soubrier F, Corvol $\mathrm{P}$, Fraser $\mathrm{R}$ et al. The angiotensin I converting enzyme gene and predisposition to high blood pressure. Hypertension 1993; 21: 455-460

113. Brodie C, Gelfand EW. Functional nerve growth factor receptors on human B lymphocytes: Interaction with IL2. JImmunol 1992; 148: 3492-3497

114. Chaldakov GN, Ghenev PI, Valchanov K, Tonchev A, Pancheva R. Nerve-mast cell-nerve growth factor link: the mast cell as yin-yang modulator in inflammation and fibrosis. BiomedRev 1995; 4: 1-6

115. Aloe L, Tuveri M-A, Angelucci F. Nerve growth factor, mast cells and arthritis. BiomedRev 1995: 4: 7-14

116. Scully JL, Otten U. NGF: Not just for neurons. Cell Biol Int 1995; 19: 459-470

117. Brodie C, Oshiba A, Renz H, Bradley K, Gelfand EW. Nerve growth factor and anti-CD40 provide opposite signals for the production of IgE in interleukin-4-treated lymphocytes. Eur JImmunol 1996; 26: 171-178

118. Kannan Y, Bienenstock J, Ohta M, Stanisz AM, Stead RH. Nerve growth factor and cytokines mediate lymphoid tissue-induced neurite outgrowth from mouse superior cervical ganglia in vitro. JImmunol 1996; 157: 313-320

119. Torcia M, Bracci-Landiero L, Lucibello M, Nencioni L, Labardi D, Rubartelli A et al. Nerve growth factor is an autocrine survival factor for memory B lymphocytes. Cell 1996; 85: 345-356

120. Ghenev PI, Chaldakov GN. Neural-immune link in adventitial remodeling in human coronary atherosclerosis [letter]. Circulation 1997; In press

121. Scuteri A, Jensen PE, Aalkjaer C. The regulation of $\mathrm{pH}$ in resistance arteries from spontaneously hypertensive and Wistar-Kyoto rats: the effect of bicarbonate. JHypertens 1995; 13: 523-528

122. Wang R, Sauve R, De Champlain J. Altered calcium homeostasis in tail artery endothelial cells from spontaneously hypertensive rats. Am J Hypertens 1995; 8: 1023 1030

123. Horn J-L, Janicki PK, Franks JJ. Diminished brain synaptic plasma membrane $\mathrm{Ca}^{2+}$-ATPase activity in spontaneously hypertensive rats: association with reduced anesthetic requirements. Life Sci 1995; 56: PL427-PL432
124. Ohbu K, Hendley ED, Yamaguchi I, Felder RA. Renal dopamine-1 receptors in hypertensive rat strains with and without hyperactivity. Hypertension 1993; 21: 485-490

Received 28 August 1996 Accepted 30 September 1996

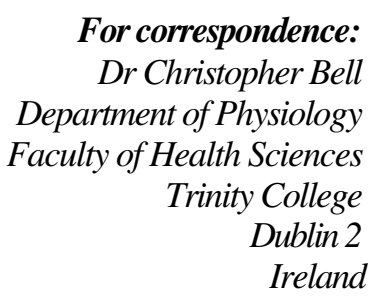

Tel: $353(1) 6081226$

Fax: 353(1)6081486

E-mail: cbell@mail.tcd.ie 